\title{
Sustentabilidade de propriedades familiares no agreste meridional de Pernambuco - uma aplicação do método MESMIS
}

Sustainability of family properties in the southeastern Pernambuco - an application of the MESMIS method

Sostenibilidad de las propiedades familiares en el sur rural de Pernambuco: una aplicación del método MESMIS

\section{Resumo}

A busca por ações mitigadoras da degradação ambiental causada pelo modelo agrícola convencional vigente tem estimulado o uso de indicadores, os quais auxiliam tomadas de decisões e contribuem para a sustentabilidade dos agroecossistemas. Assim, o objetivo desse estudo foi avaliar a sustentabilidade de propriedades familiares. A pesquisa ocorreu em dez propriedades dos municípios pernambucanos: Bom Conselho, Garanhuns, Jucati e Saloá. Optou-se pelo método MESMIS, o qual resultou nos seguintes resultados: a caracterização dos agroecossistemas traçou um panorama geral e a relação dos agricultores com os agroecossistemas; a análise dos pontos críticos apontou fatores que interferem na sustentabilidade como a mão de obra, assistência técnica, solo e água; a construção dos indicadores levou em consideração a opinião dos agricultores, pontos críticos, estudo de literatura, atributos e as três dimensões centrais da sustentabilidade (ambiental, econômica e social). Após a aplicação dos indicadores, todos os agroecossistemas alcançaram média geral de sustentabilidade regular, necessitando de melhora em aspectos como qualidade do solo, falta de água, assistência técnica e manejo agroecológico. O método utilizado se apresenta como uma ferramenta de autogestão capaz de avaliar a situação atual de um agroecossistema, bem como, subsidiar técnicas que visem a sustentabilidade.

Palavras-chave: Agricultura familiar; Desenvolvimento sustentável; Indicadores de sustentabilidade.

\begin{abstract}
The search for actions to mitigate environmental degradation caused by the current conventional agricultural model has encouraged the use of indicators, which help decision-making and contribute to the sustainability of agroecosystems. Thus, the aim of this study was to assess the sustainability of family properties. The research took place in ten properties in Pernambuco's municipalities: Bom Conselho, Garanhuns, Jucati and Saloá. The MESMIS method was chosen, which resulted in the following results: the characterization of the agroecosystems drew a general panorama and the relationship between farmers and agroecosystems; the analysis of critical points pointed out factors that interfere with sustainability such as labor, technical assistance, soil and water; the construction of indicators took into account the opinion of farmers, critical points, literature study, attributes and the three central dimensions of sustainability (environmental, economic and social). After applying the indicators, all agroecosystems achieved an overall average of regular sustainability, requiring improvement in aspects such as soil quality, lack of water, technical assistance and agroecological management. The method used is presented as a self-management tool capable of evaluating the current situation of an agroecosystem, as well as subsidizing techniques aimed at sustainability.

Keywords: Family farming; Sustainable development; Sustainability indicators.
\end{abstract}




\begin{abstract}
Resumen
La búsqueda de acciones para mitigar la degradación ambiental provocada por el modelo agrícola convencional actual ha incentivado el uso de indicadores, que ayudan a la toma de decisiones y contribuyen a la sostenibilidad de los agroecosistemas. Por tanto, el objetivo de este estudio fue evaluar la sostenibilidad de las propiedades familiares. La investigación se llevó a cabo en diez propiedades de los municipios de Pernambuco: Bom Conselho, Garanhuns, Jucati y Saloá. Se eligió el método MESMIS, que arrojó los siguientes resultados: la caracterización de los agroecosistemas trazó un panorama general y la relación entre agricultores y agroecosistemas; el análisis de puntos críticos señaló factores que interfieren con la sustentabilidad tales como mano de obra, asistencia técnica, suelo y agua; La construcción de indicadores tomó en cuenta la opinión de los agricultores, puntos críticos, estudio de la literatura, atributos y las tres dimensiones centrales de la sostenibilidad (ambiental, económica y social). Luego de aplicar los indicadores, todos los agroecosistemas lograron un promedio general de sustentabilidad regular, requiriendo mejoras en aspectos como la calidad del suelo, falta de agua, asistencia técnica y manejo agroecológico. El método utilizado se presenta como una herramienta de autogestión capaz de evaluar la situación actual de un agroecosistema, así como de subsidiar técnicas orientadas a la sostenibilidad.
\end{abstract}

Palabras clave: Agricultura familiar; Desarrollo sostenible; Indicadores de sostenibilidad.

\title{
1. Introdução
}

Recentemente tem-se observado uma crescente preocupação com as questões ambientais e a busca por ações efetivas mitigadoras da degradação causada pelo modelo agrícola convencional vigente. Uma das formas de atenuar os problemas ambientais é a utilização de indicadores ambientais, os quais devem auxiliar nas tomadas de decisões e contribuir para uma maior sustentabilidade de sistemas produtivos (Paoli et al., 2015; Pilouk \& Koottatep, 2017; Nascimento et al., 2018). O uso de indicadores elaborados por instituições públicas e privadas para avaliação do desenvolvimento sustentável de sistemas produtivos tem-se multiplicado. Normalmente, os indicadores incorporam diferentes dimensões, como aspectos econômicos, fatores sociais, diversidade cultural, influência política e outros. Ressalta-se a necessidade de criação de indicadores objetivos e mensuráveis para as diversas cadeias produtivas (Hirakuri et al., 2014). Os indicadores devem ser mensuráveis e aplicáveis nos mais diversos ecossistemas, permitindo a participação da população local, sendo sensíveis às mudanças da natureza, possibilitando a integração com outros indicadores e representando padrões de sustentabilidade. Nesse sentido, quando bem elaborados, os indicadores possibilitam o monitoramento da transição agroecológica a baixo custo, permitindo mensurar processos em escala temporal e espacial, e por fim, identificar as causas de degradação ambiental e de potenciais para a sustentabilidade do agroecossistema (Ferraz, 2003; Saradón \& Flores, 2009).

Comumente a avaliação da sustentabilidade dos agroecossistemas familiares engloba temas como a sucessão familiar, comercialização, extensão rural, redes de conhecimento, uso do solo, qualidade da água, dentre outros. Ressalta-se os esforços do uso de indicadores direcionados a gestão ambiental, apresentando assim, uma ferramenta que pode tornar mais efetivo o monitoramento da sustentabilidade dos agroecossistemas (Souza, Martins \& Verona, 2017). Estratégias voltadas à promoção do desenvolvimento rural sustentável devem considerar as seguintes dimensões relacionadas entre si: ecológica, econômica, social (primeiro nível), cultural, política (segundo nível) e ética (terceiro nível). Mesmo não havendo um estudo conclusivo sobre um tema tão complexo, compreende-se que estas dimensões podem ser úteis na definição de indicadores para o monitoramento de contextos da sustentabilidade alcançados num dado momento (Caporal \& Costabeber, 2002).

O MESMIS - Marco para Evaluación de Sistemas de Manejo de Recursos Naturales Incorporando Indicadores de Sustentabilidad - desponta como uma proposta metodológica participativa e interdisciplinar, desenvolvida pelo Grupo Interdisciplinar de tecnologia Rural Aplicada (GIRA), do México, tendo como seus principais idealizadores Omar Masera, Marta Astier e Santiago López-Ridaura, autores do livro Sustentabilidad y manejo de recursos naturales: el marco de evaluación (Masera, Astier \& López-Ridaura, 1999). De acordo com Verona (2008) esse método é flexível, o que possibilita a realização de adaptações metodológicas durante o processo de avaliação da sustentabilidade em sistemas agrícolas. Além disso, o MESMIS incentiva adaptações específicas, reconhecendo as especificidades de cada estudo. Essa metodologia pode oferecer uma visão mais completa do agroecossistema estudado (Gliessman, 2014). Porém atributos classificados como 
“disciplinares” pelos autores como a autossuficiência não estão incluídos. Portanto, em relação a esse aspecto, é possível que o MESMIS possua falha (Lopéz-Ridaura et al., 2005).

Matos Filho (2004) ressalta que a proposta MESMIS é baseada em algumas premissas: $1^{\circ}$ ) $\mathrm{O}$ conceito de sustentabilidade para agroecossistemas é definido por cinco atributos básicos: a) produtividade; b) estabilidade, resiliência e confiabilidade; c) adaptabilidade; d) equidade; e) autogestão. $2^{\circ}$ ) A avaliação de sustentabilidade é válida, apenas, para situações definidas em um determinado espaço geográfico, sistema de manejo, contexto social e político, escala espacial (parcela, unidade de produção, comunidade, bacia hidrográfica), e em uma escala temporal. $3^{\circ}$ ) A avaliação é uma atividade participativa, com perspectiva e trabalho multidisciplinar. O seu emprego tem ocorrido em diversas partes do mundo, principalmente em casos de agricultura familiar ou campesina, com ênfase em atividades com base ecológica, como por exemplo o estudo realizado por Losada, Gómez-Ramos, e Rico, (2019) que avaliaram em termos de sustentabilidade, a percepção das partes envolvidas em áreas rurais da Espanha Central. Chaparro-Africano (2019) sugeriu alguns indicadores de sustentabilidade para uma rede de mercados agroecológicos da região de Bogotá e Alcázar e Espejel (2019) propuseram uma avaliação retrospectiva da sustentabilidade de uma fazenda diversificada no Vale de Guadalupe, México.

Diante do supracitado, esta pesquisa teve por objetivo avaliar a sustentabilidade de propriedades familiares na região do Agreste Meridional de Pernambuco a partir da compreensão das relações socioeconômicas e ambientais. E por fim, no âmbito da tomada de decisão, foi proposto oferecer aos agricultores, pesquisadores e extensionistas uma ferramenta viável de autogestão da propriedade agrofamiliar.

\section{Metodologia}

Entre março de 2019 e setembro de 2020, foram avaliadas dez propriedades familiares nos municípios de Bom Conselho, Garanhuns, Jucati e Saloá, ambos localizados na região do Agreste Meridional de Pernambuco (Figura 1). Ressaltase que propriedades pertencem a participantes de uma feira agroecológica, realizada semanalmente na cidade de Garanhuns/PE.

Figura 1 - Localização dos municípios de Bom Conselho, Garanhuns, Jucati e Saloá, no Agreste Meridional de Pernambuco.

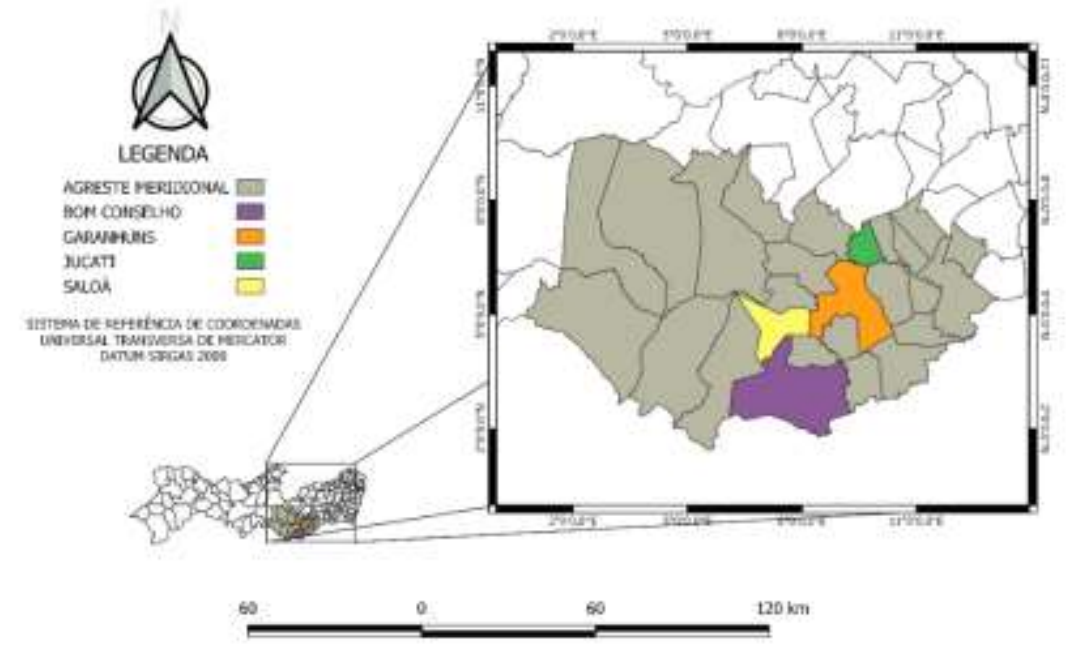

Fonte: Autores.

Para avaliação da sustentabilidade dos agroecossistemas, foi utilizada a metodologia do MESMIS, que permite um processo de avaliação cíclico, participativo, sistêmico, multiescalar e adaptável a diferentes contextos, contribuindo com 
elementos determinantes para a sustentabilidade dos sistemas avaliados (Chaparro-Africano, 2019). Tal metodologia utiliza-se de indicadores qualitativos e quantitativos, os quais costumam ser apresentados em gráficos do tipo radar (ou ameba).

Tais representações gráficas são adequadas ao público-alvo dos métodos, pois facilitam a leitura e interpretação dos indicadores, permitindo identificar prontamente os pontos fortes e fracos da unidade produtiva, podendo ser utilizadas não só pelos agricultores como também pelos demais pesquisadores da área para guiar políticas e priorizar ações corretivas (Nicholls et al., 2004; Bélanger et al., 2012). Esse instrumento auxilia os agricultores a refletir sobre suas estratégias de gestão de forma holística facilitando a comparação dos sistemas analisados (Astier \& Hollans, 2005; Acosta-Alba \& Werf, 2011). A aplicação do MESMIS seguiu as seguintes etapas:

$1^{\mathrm{a}}$ etapa: Caracterização dos agroecossistemas - foram realizados estudos detalhados dos agroecossistemas em avaliação, identificando os sistemas de manejo, suas características e contexto socioeconômico e ambiental;

$2^{\mathrm{a}}$ etapa: Análise dos pontos críticos e de destaque - identificação dos fatores que limitam ou favorecem a sustentabilidade;

$3^{\mathrm{a}}$ etapa: Seleção dos indicadores de sustentabilidade - a construção dos indicadores compostos se deu de forma participativa com os produtores investigados. Os indicadores também determinados a partir do critério "relevância", que os agricultores consideram como importantes para se avaliar em suas propriedades, como também, foi levado em consideração os pontos críticos e de destaque e o estudo de literatura. Tais indicadores foram determinados a partir dos três pilares centrais da sustentabilidade: ambiental, econômico e social;

$4^{\mathrm{a}}$ etapa: Mensuração dos indicadores - foram formulados instrumentos de avaliação com o objetivo de quantificar as informações desejadas, de origem qualitativas e quantitativas;

$5^{\text {a }}$ etapa: Síntese e integração dos resultados - para uma melhor visualização dos resultados foram construídos gráficos do tipo radial (ameba). Ainda nessa etapa, foram identificados os principais obstáculos e os aspectos que favorecem a sustentabilidade; $6^{a}$ etapa: Indicações gerais para os agroecossistemas - foi feita uma síntese da avaliação e sugestões de alternativas para fortalecer a sustentabilidade dos agroecossistemas, possibilitando a melhora do processo de avaliação em aplicação de trabalhos futuros.

Para coleta dos dados, foram aplicados questionários estruturados (com 38 indicadores/perguntas) aos agricultores envolvidos (um representante por propriedade), com duração de cerca de 1 (uma) hora, não havendo uma pré-entrevista, mas sim, um breve convívio com os participantes via feira agroecológica. Este tipo de pesquisa pode ser descrita como a obtenção de dados ou informações sobre características, ações ou opiniões de um determinado grupo de pessoa, sendo denominada de "survey" (Pinsonneault \& Kraemer, 1993).

No âmbito de preservar a privacidade dos agricultores e melhorar a organização das informações, as propriedades avaliadas receberam as seguintes nomenclaturas: Agroecossistema 1 (AG1); Agroecossistema 2 (AG2); Agroecossistema 3 (AG3); Agroecossistema 4 (AG4); Agroecossistema 5 (AG5); Agroecossistema 6 (AG6); Agroecossistema 7 (AG7); Agroecossistema 8 (AG8); Agroecossistema 9 (AG9); Agroecossistema 10 (AG10).

\section{Resultados e Discussão}

\subsection{Caracterização dos Agroecossistemas}

Características gerais: Todas as propriedades se encontram em transição agroecológica. Os agricultores participam da organização da feira agroecológica - a Agrofeira, para comercialização dos produtos, que é realizada em parceria com o Núcleo Agrofamiliar, da Universidade Federal Rural de Pernambuco/Universidade Federal do Agreste de Pernambuco - 
UFAPE/UFRPE, e ocorre na cidade de Garanhuns/Pernambuco. Ainda por meio desta parceria, os agricultores são acompanhados e capacitados por professores e alunos da universidade.

Quadro 1 - Caracterização individual dos agroecossistemas.

\begin{tabular}{|c|c|c|c|c|c|c|c|}
\hline AG & Local & $\begin{array}{l}\text { Extensão/Moradores/ } \\
\text { Escolaridade }\end{array}$ & $\begin{array}{l}\text { Geografia/Solo/Água/Saneamen } \\
\text { to }\end{array}$ & Produção Vegetal & $\begin{array}{l}\text { Produçã } \\
\text { o animal }\end{array}$ & $\begin{array}{l}\text { Práticas } \\
\text { conservacionistas }\end{array}$ & Renda e gastos \\
\hline AG1 & $\begin{array}{l}\text { Sítio } \\
\text { Cruz, } \\
\text { Garanhu } \\
\text { ns }\end{array}$ & \begin{tabular}{lr}
\multicolumn{1}{c}{ hectares; } & 2 \\
residências; & 4 \\
moradores & (dois \\
homens e & duas \\
mulheres); & \\
escolaridades & variam \\
de ensino fundamental \\
incompleto a ensino \\
médio/técnico \\
completo.
\end{tabular} & $\begin{array}{l}\text { Área plana com uma leve } \\
\text { declividade; solo arenoso; água } \\
\text { oriunda de poço artesanal e } \\
\text { barreiro, ambos protegidos por } \\
\text { vegetação em suas proximidades; } \\
\text { fossa séptica para captação de } \\
\text { esgoto; coleta domiciliar do lixo; } \\
\text { reciclagem de alguns resíduos; } \\
\text { sistemas de microaspersão e } \\
\text { gotejamento. }\end{array}$ & $\begin{array}{lr}\text { Coentro; } & \text { cebolinha; } \\
\text { alface; } & \text { cenoura; } \\
\text { beterraba; } & \text { couve; } \\
\text { feijão; } & \text { milho; } \\
\text { mandioca; } & \text { laranja; } \\
\text { limão; } & \text { acerola; } \\
\text { goiaba; manga; } & \text { graviola; hibisco; } \\
\text { capim-santo; } \\
\text { hortelã; manjericão; } \\
\text { e alecrim. }\end{array}$ & $\begin{array}{l}\text { Gados; e } \\
\text { galinhas. }\end{array}$ & $\begin{array}{l}\text { Consorciação de } \\
\text { culturas; adubação } \\
\text { orgânica; e uso de } \\
\text { defensivos } \\
\text { alternativos }\end{array}$ & $\begin{array}{l}\text { A renda é obtida da } \\
\text { venda da produção } \\
\text { agrícola e é } \\
\text { complementada com } \\
\text { atividade r de } \\
\text { assistência récnica } \\
\text { agrícola. ras } \\
\text { principais gastos são } \\
\text { com energia elétrica } \\
\text { e combustível. }\end{array}$ \\
\hline AG2 & $\begin{array}{l}\text { Sítio } \\
\text { Cruz, } \\
\text { Garanhu } \\
\text { ns }\end{array}$ & $\begin{array}{l}1,5 \text { hectares; } 2 \\
\text { mulheres adultas; } \\
\text { ensino fundamental } \\
\text { incompleto. }\end{array}$ & $\begin{array}{l}\text { Área plana, de baixada, possuindo } \\
\text { declividade em alguns pontos; } \\
\text { solo areno-argiloso; água é } \\
\text { oriunda de um poço artesanal, } \\
\text { preservado com vegetação ao seu } \\
\text { entorno; irrigação do tipo } \\
\text { microaspersão e gotejamento; } \\
\text { existência de fossa séptica para } \\
\text { captação de esgoto; coleta } \\
\text { domiciliar do lixo; reciclagem de } \\
\text { alguns resíduos orgânicos. }\end{array}$ & $\begin{array}{lr}\text { Alface; } & \text { rúcula; } \\
\text { coentro; } & \text { couve; } \\
\text { pimentão; } & \text { cebola; } \\
\text { beterraba; } & \text { cenoura; } \\
\text { feijão; } & \text { milho; } \\
\text { acerola, } & \text { laranja; } \\
\text { manga; } & \text { pitanga; } \\
\text { goiaba; seriguela; } \\
\text { erva-cidreira; } \\
\text { capim-santo; } \\
\begin{array}{l}\text { hortelã; capim de } \\
\text { corte; e palma. }\end{array}\end{array}$ & $\begin{array}{l}\text { Gados; } \\
\text { ovinos; e } \\
\text { galinhas. }\end{array}$ & $\begin{array}{l}\text { Consorciação de } \\
\text { culturas; cultivo } \\
\text { em nível; } \\
\text { defensivos } \\
\text { alternativos; e } \\
\begin{array}{l}\text { adubação } \\
\text { orgânica. }\end{array}\end{array}$ & $\begin{array}{l}\text { A renda é oriunda da } \\
\text { venda dos produtos } \\
\text { cultivados na } \\
\text { propriedader e } \\
\text { complementada com } \\
\text { aposentadoria rural } \\
\text { das moradoras. Os } \\
\text { principais gastos são } \\
\text { advindos da compra } \\
\text { de combustível e } \\
\text { serviços de saúde. }\end{array}$ \\
\hline AG3 & $\begin{array}{l}\text { Sítio } \\
\text { Cruz, } \\
\text { Garanhu } \\
\text { ns }\end{array}$ & $\begin{array}{l}2,5 \text { hectares; } 3 \text { pessoas } \\
\text { adultas (dois homens e } \\
\text { uma mulher); } \\
\text { escolaridade que varia } \\
\text { de ensino fundamental } \\
\text { incompleto a superior } \\
\text { completo. }\end{array}$ & $\begin{array}{l}\text { Área plana, possuindo declividade } \\
\text { em alguns pontos; solo arenoso.; } \\
\text { água retirada de um poço } \\
\text { artesanal, onde não apresenta } \\
\text { vegetação em suas proximidades; } \\
\text { irrigação do tipo microaspersão; } \\
\text { fossa séptica para captação de } \\
\text { esgoto; coleta domiciliar do lixo; } \\
\text { reciclagem de alguns resíduos; } \\
\text { queima de lixo na propriedade. }\end{array}$ & $\begin{array}{lr}\text { Coentro; } & \text { couve; } \\
\text { pimentão; } & \text { feijão; } \\
\text { milho; } & \text { laranja; } \\
\text { limão; } & \text { manga; } \\
\text { jaboticaba; e capim- } \\
\text { santo. }\end{array}$ & Galinhas. & \begin{tabular}{lr}
\multicolumn{2}{l}{ Cultivo em nível; } \\
consorciação & de \\
culturas; & $\mathrm{e}$ \\
adubação & \\
orgânica.
\end{tabular} & $\begin{array}{l}\text { A reanda é obtida a } \\
\text { partir da venda da } \\
\text { produção agrícola e } \\
\text { complementada com } \\
\text { uma aposentadoria } \\
\text { rural. Os principais } \\
\text { gastos são com a } \\
\text { compra de esterco } \\
\text { bovino. }\end{array}$ \\
\hline AG4 & $\begin{array}{l}\text { Sítio } \\
\text { Cruz, } \\
\text { Garanhu } \\
\text { ns }\end{array}$ & $\begin{array}{l}\text { 1,5 hectares; } 2 \text { adultos } \\
\text { (um homem e uma } \\
\text { mulher); } \\
\text { fundamental } \\
\text { incompleto. }\end{array}$ & $\begin{array}{l}\text { Área plana, com leve declividade; } \\
\text { solo arenoso; água advinda de } \\
\text { poço artesanal, possuindo pouca } \\
\text { vegetação ao seu redor; fossa } \\
\text { séptica para captação de esgoto; } \\
\text { coleta domiciliar do lixo; } \\
\text { reciclagem; queima de lixo. }\end{array}$ & $\begin{array}{lr}\text { Feijão; } & \text { milho; } \\
\text { laranja; } & \text { manga; } \\
\text { hortelã; } & \text { capim- } \\
\text { santo; canela; e } & \text { erva-cidreira. }\end{array}$ & Galinhas. & $\begin{array}{l}\text { Cultivo em nível; } \\
\text { adubação } \\
\begin{array}{l}\text { orgânica; } \\
\text { consorciação de } \\
\text { culturas. }\end{array}\end{array}$ & $\begin{array}{l}\text { A renda é obtida } \\
\text { apenas da venda da } \\
\text { produção agrícola e o } \\
\text { principal gasto é com } \\
\text { a compra de esterco } \\
\text { bovino. }\end{array}$ \\
\hline AG5 & $\begin{array}{l}\text { Sitio } \\
\text { Flameng } \\
\text { o, } \\
\text { Garanhu } \\
\text { ns }\end{array}$ & $\begin{array}{lr}7 \quad \text { hectares; } & 4 \\
\text { moradores } & \text { (dois } \\
\text { homens e } & \text { duas } \\
\text { mulheres); } & \\
\text { escolaridade que varia } \\
\text { de ensino fundamental } \\
\text { incompleto } \\
\text { completo. }\end{array}$ & $\begin{array}{l}\text { Área plana, possuindo pouca } \\
\text { declividade; solo areno-argiloso; } \\
\text { água oriunda de poço artesanal, o } \\
\text { qual possui proteção com } \\
\text { vegetação ao seu redor; sistema } \\
\text { de irrigação do tipo } \\
\text { microaspersão; fossa séptica para } \\
\text { coleta de dejetos; coleta } \\
\text { domiciliar de lixo. }\end{array}$ & $\begin{array}{lr}\text { Coentro; } & \text { couve; } \\
\text { espinafre; } & \text { alho-poró; } \\
\text { caju; } & \text { manga; } \\
\text { jaboticaba; } & \text { limão; } \\
\text { goiaba; } & \text { culturas; } \\
\text { feijão; } & \text { milho; } \\
\text { mandioca. } & \end{array}$ & $\begin{array}{l}\text { Gados; } \\
\text { carneiros; } \\
\text { galinhas; } \\
\text { e abelhas. }\end{array}$ & $\begin{array}{l}\text { Consorciação de } \\
\text { culturas; adubação } \\
\text { orgânica; cultivo } \\
\text { em nível; e o uso } \\
\text { de defensivos } \\
\text { naturais. }\end{array}$ & $\begin{array}{l}\text { A renda é obtida a } \\
\text { partir da venda dos } \\
\text { produtos } \\
\text { agropecuários e } \\
\text { complementada com } \\
\text { salário de prestação } \\
\text { de serviço externo e } \\
\text { aposentadoria rural. } \\
\text { Os principais gastos } \\
\text { são com ração } \\
\text { animal. }\end{array}$ \\
\hline AG6 & $\begin{array}{l}\text { Distrito } \\
\text { Brejo } \\
\text { Velho, } \\
\text { Saloá/PE }\end{array}$ & $\begin{array}{l}\text { 1,5 hectares; } 2 \text { adultos } \\
\text { (um homem e uma } \\
\text { mulher); ensino } \\
\text { fundamental } \\
\text { incompleto. }\end{array}$ & $\begin{array}{l}\text { Área plana, com pouca } \\
\text { declividade; solo arenoso; poço } \\
\text { artesanal, o qual possui vegetação } \\
\text { ao seu redor; sistema de irrigação } \\
\text { de gotejamento; fossa séptica para } \\
\text { coleta do esgoto; coleta domiciliar } \\
\text { de lixo. }\end{array}$ & $\begin{array}{l}\text { Mandioca; manga; } \\
\text { jaca; e palma. }\end{array}$ & $\begin{array}{l}\text { Caprinos; } \\
\text { e ovinos. }\end{array}$ & $\begin{array}{l}\text { Consorciação de } \\
\text { culturas; plantio } \\
\text { em nível; e uso de } \\
\text { adubos orgânicos. }\end{array}$ & $\begin{array}{l}\text { A renda é obtida a } \\
\text { partir da venda dos } \\
\text { produtos } \\
\text { agropecuários e } \\
\text { complementada com } \\
\text { aposentadoria rural. } \\
\text { Os principais gastos } \\
\text { são com ração } \\
\text { animal, gasolina e } \\
\text { energia elétrica. }\end{array}$ \\
\hline AG7 & $\begin{array}{l}\text { Distrito } \\
\text { de } \\
\text { Rainha } \\
\text { Isabel, } \\
\text { Bom }\end{array}$ & $\begin{array}{l}7 \text { hectares; } 2 \text { dois } \\
\text { adultos (um homem e } \\
\text { uma mulher); ensino } \\
\text { fundamental } \\
\text { incompleto. }\end{array}$ & $\begin{array}{l}\text { Área plana, com pouca } \\
\text { declividade; solo argiloso; água é } \\
\text { obtida de uma cacimba; não } \\
\text { possuem sistema de irrigação; } \\
\text { fossa séptica para captação dos }\end{array}$ & $\begin{array}{l}\text { Banana; abacate; } \\
\text { acerola; mamão; e } \\
\text { batata doce. }\end{array}$ & Galinhas. & Cultivo em nível. & $\begin{array}{l}\text { A renda é oriunda da } \\
\text { venda dos produtos } \\
\text { agrícolas e os } \\
\text { principais gastos são } \\
\text { com a contratação de }\end{array}$ \\
\hline
\end{tabular}




\begin{tabular}{|c|c|c|c|c|c|c|c|}
\hline & Conselho & & dejetos; lixo é destinado a queima. & & & & mão de obra externa. \\
\hline AG8 & $\begin{array}{l}\text { Comunid } \\
\text { ade do } \\
\text { Castaính } \\
\text { o, } \\
\text { Garanhu } \\
\text { ns }\end{array}$ & $\begin{array}{l}1 \text { hectare; } 1 \text { mulher, } \\
\text { que possui ensino } \\
\text { superior completo e } \\
\text { uma criança do sexo } \\
\text { masculino, cursando o } \\
\text { ensino fundamental. }\end{array}$ & $\begin{array}{l}\text { Área plana; solo areno-argiloso; } \\
\text { água obtida de poço artesanal, } \\
\text { protegido por vegetação ao seu } \\
\text { redor; não possui sistema de } \\
\text { irrigação; fossa séptica para } \\
\text { captação do esgoto; coleta } \\
\text { domiciliar de lixo. }\end{array}$ & $\begin{array}{l}\text { Mandioca; milho; } \\
\text { feijão; manga; } \\
\text { abacate; seriguela. }\end{array}$ & $\begin{array}{l}\text { Não há } \\
\text { criação } \\
\text { de } \\
\text { animais. }\end{array}$ & $\begin{array}{l}\text { Consorciação de } \\
\text { culturas; adubação } \\
\text { orgânica; e o uso } \\
\text { de defensivos } \\
\text { naturais. }\end{array}$ & $\begin{array}{l}\text { A renda é obtida da } \\
\text { venda dos produtos } \\
\text { agrícola, bem como, } \\
\text { do beneficiamento da } \\
\text { mandioca (goma, } \\
\text { beiju e bolo), e é } \\
\text { complementada por } \\
\text { atividade externa, } \\
\text { como professora. O } \\
\text { principal gasto é com } \\
\text { a compra de } \\
\text { embalagem. }\end{array}$ \\
\hline AG9 & $\begin{array}{l}\text { Sitio } \\
\text { Mandant } \\
\text { e, } \\
\text { Garanhu } \\
\text { ns }\end{array}$ & $\begin{array}{l}4,4 \text { hectares; } 4 \text { pessoas } \\
\text { (um casal de adultos, } \\
\text { uma adolescente e } \\
\text { uma criança, ambas do } \\
\text { sexo feminino); ensino } \\
\text { fundamental } \\
\text { incompleto. }\end{array}$ & $\begin{array}{l}\text { Área plana, com pouca } \\
\text { declividade; o solo arenoso; poço } \\
\text { artesanal, sem proteção ao seu } \\
\text { redor; sistema de irrigação de } \\
\text { gotejamento; fossa séptica para } \\
\text { captação de esgoto; queima do } \\
\text { lixo. }\end{array}$ & $\begin{array}{lr}\text { Alface; } & \text { coentro; } \\
\text { pimentão; } & \text { feijão; } \\
\text { mandioca; e milho. }\end{array}$ & Gados. & $\begin{array}{l}\text { Adubação } \\
\text { orgânica; cultivo } \\
\text { em nível; } \\
\text { consorciação de } \\
\text { culturas; } \\
\text { defensivos } \\
\text { naturais. }\end{array}$ & $\begin{array}{l}\text { A renda é obtida da } \\
\text { atividade } \\
\text { agropecuária, e o } \\
\text { seus principais gastos } \\
\text { são com energia } \\
\text { elétrica e r a } \\
\text { contratação de mão } \\
\text { de obra externa. }\end{array}$ \\
\hline AG10 & $\begin{array}{l}\text { Distrito } \\
\text { de } \\
\text { Neves, } \\
\text { Jucati }\end{array}$ & $\begin{array}{l}\text { 0,5 hectares; } 5 \text { pessoas } \\
\text { (um casal de adultos, } \\
\text { uma adolescente e } \\
\text { uma criança do sexo } \\
\text { feminino); } \\
\text { escolaridades que } \\
\text { variam entre ensino } \\
\text { fundamental } \\
\text { incompleto e ensino } \\
\text { médio completo. }\end{array}$ & $\begin{array}{l}\text { A ligeiramente declive; solo } \\
\text { argiloso; água é obtida da compra } \\
\text { externa e da captação da chuva } \\
\text { em cisterna; sistema de irrigação } \\
\text { de gotejamento; fossa séptica para } \\
\text { coleta do esgoto; e coleta } \\
\text { domiciliar de lixo. }\end{array}$ & $\begin{array}{lr}\text { Coentro; } & \text { cebolinha; } \\
\text { alface; } & \text { goiaba; } \\
\text { umbu; e acerola. }\end{array}$ & $\begin{array}{l}\text { Gados; e } \\
\text { galinhas. }\end{array}$ & $\begin{array}{l}\text { Cultivo em nível; } \\
\text { consorciação de } \\
\text { culturas; adubação } \\
\text { orgânica; uso de } \\
\text { defensivos } \\
\text { naturais. }\end{array}$ & $\begin{array}{l}\text { A renda é obtida } \\
\text { exclusivamente da } \\
\text { venda dos produtos } \\
\text { agropecuários e o } \\
\text { principal gasto é com } \\
\text { a compra de água. }\end{array}$ \\
\hline
\end{tabular}

Fonte: Dados da pesquisa.

\subsection{Análise dos Pontos Críticos e de Destaque}

Os agricultores citaram pontos que implicam ou favorecem a sustentabilidade dos agroecossistemas, (Tabela 1). A indicação dos pontos críticos serve como um parâmetro que pode ajudar a sanar os principais gargalos durante o processo de transição agroecológica.

Tabela 1 - Principais pontos críticos apontados pelos agricultores.

\begin{tabular}{lll}
\hline \multicolumn{2}{c}{ Pontos Críticos e de Destaque } \\
\hline FG1 & Disponibilidade de água e capacitação técnica. & $\begin{array}{l}\text { Desfavoráveis } \\
\text { Baixa qualidade do solo, pouca disponibilidade } \\
\text { de água nos períodos mais secos do ano. }\end{array}$ \\
\hline AG2 & $\begin{array}{l}\text { Baixa necessidade de mão de obra externa, } \\
\text { disponibilidade de água e as capacitações } \\
\text { técnicas. }\end{array}$ & $\begin{array}{l}\text { Falta de mais tecnologias agroecológicas para } \\
\text { controle de algumas pragas. }\end{array}$ \\
\hline AG3 & Disponibilidade de água. & $\begin{array}{l}\text { Falta de mais tecnologias para o controle das } \\
\text { pragas. }\end{array}$ \\
\hline AG4 & Organização comercial da feira agroecológica. & Falta de crédito e de água em certas épocas. \\
\hline AG5 & Acesso a propriedade e diversidade. & Falta de crédito para maiores investimentos. \\
\hline AG6 & Disponibilidade de água. & Falta de controle dos dados financeiros. \\
\hline AG8 & Disponibilidade de água. & Falta de crédito para investimento. \\
\hline AG9 & Disponibilidade de água. & $\begin{array}{l}\text { Disponibilidade de poucas terras para expansão } \\
\text { das atividades agrícolas. }\end{array}$ \\
\hline AG10 & Boa qualidade do solo. & Falta de assistência técnica. \\
\hline
\end{tabular}

Fonte: Dados da pesquisa. 


\subsection{Seleção dos Indicadores de Sustentabilidade}

A relação entre as dimensões de sustentabilidade, atributos, pontos críticos, critérios de diagnóstico e indicadores podem levar a inevitáveis repetições de alguns comentários e/ou processos na etapa de seleção dos indicadores. No entanto, é fundamental que ocorra essa inter-relação para que esse método alcance de uma forma mais real, a mensuração dos níveis de sustentabilidade, expressando a complexidade de um agroecossistema (Verona, 2008). Assim, seleção dos indicadores de sustentabilidade compostos (ISC) levou em consideração a sistematização dos agroecossistemas, a relação dos atributos do MESMIS, os pontos críticos e de destaque, o estudo de literatura, a discussão com os produtores e as dimensões da sustentabilidade (ambiental, econômica e social). Os indicadores compostos de sustentabilidade construídos foram: Indicador de Recursos Hídricos (IRH), Indicador do Solo (IS), Indicador de Adaptação ao Manejo do Sistema Agroecológico (IANA), Indicador de Trabalho e suas Relações (ITR), Indicador de Autogestão (IA), Indicador de Diversidade (ID) e Indicador de Situação Econômica (ISE) (Quadro 2).

Quadro 2 - Atributos, pontos críticos, critérios de diagnóstico, indicadores de sustentabilidade compostos (ISC) e dimensões utilizadas na avaliação de sustentabilidade.

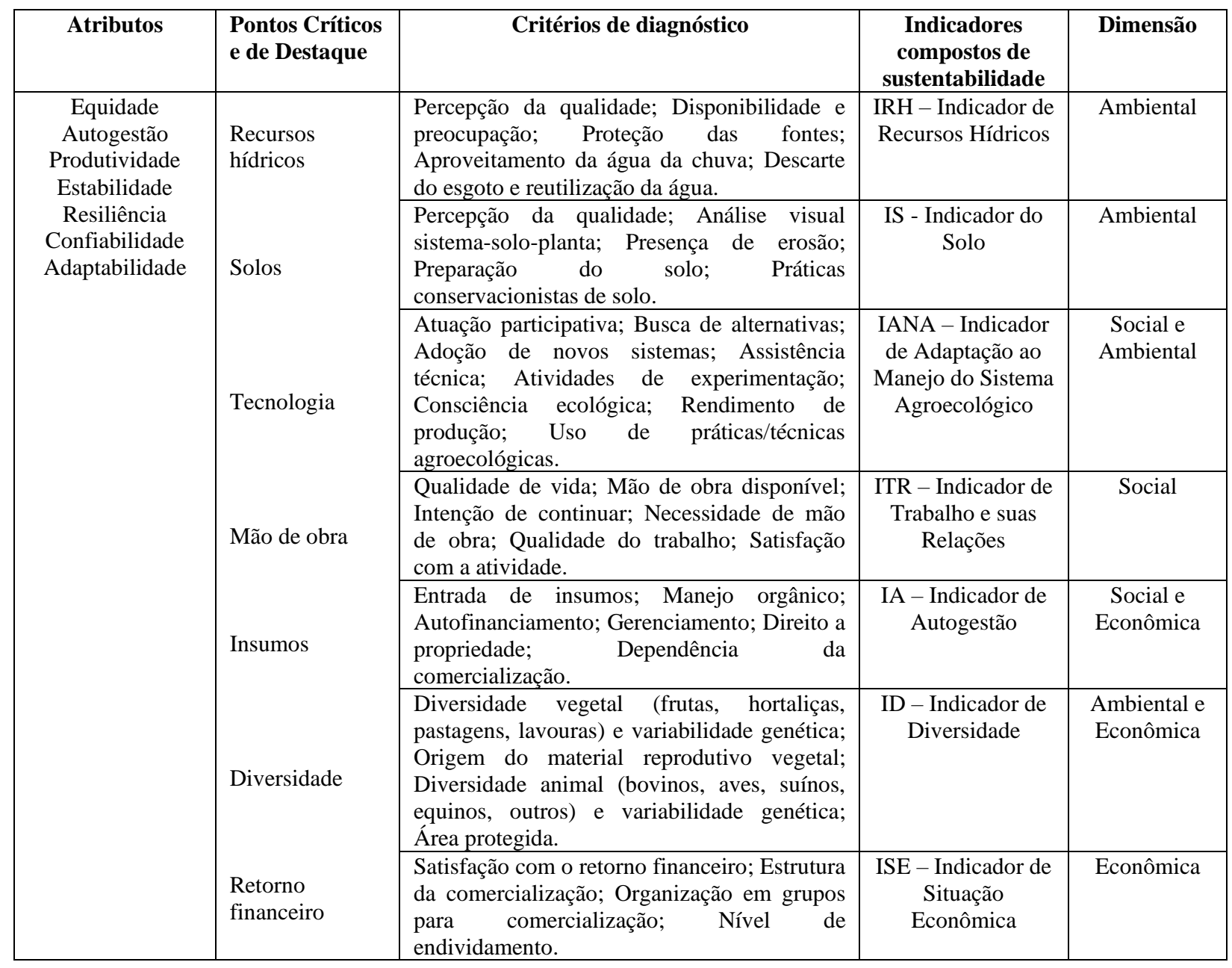

Fonte: Dados da pesquisa.

\subsection{Mensuração dos Indicadores}

A mensuração dos indicadores é fundamental para a medição e monitoramento dos indicadores de sustentabilidade. Seu principal objetivo é refletir as tendências e o comportamento dos aspectos mais relevantes na busca da sustentabilidade dos 
agroecossistemas (Masera et al., 1999). A mensuração foi estabelecida por parâmetros de avaliação padronizados, em que, os resultados de todos indicadores se expressaram em notas de 1, 2 e 3, sendo: 1 - valor ruim ou indesejável; 2 - valor regular; e 3 - valor ótimo ou desejável. Posteriormente é realizada a média de cada indicador composto e por fim, a média final do agroecossistema. A avaliação de sustentabilidade do agroecossistema realizada por meio dos indicadores ambientais é determinada a partir de parâmetros amplamente aceitos, usados pela academia e definidos em publicações científicas (Verona, 2008).

\subsection{Síntese e integração dos resultados}

Todos os agroecossistemas apresentaram médias sustentabilidade bem parecidas entre si. Tendo em vista que a avaliação dispunha de três notas (1, 2 e 3), todas propriedades familiares avaliadas apresentaram média geral superior a 2, sendo um valor de sustentabilidade regular (Figura 2). Para facilitar a visualização dos dados, os agroecossistemas foram divididos em dois grupos: grupo 1 (AG1, AG2, AG5, AG6 e AG10) que apresentaram as médias igual ou superior a 2,4 (Figura 3); e o grupo 2 (AG3, AG4, AG7, AG8 e AG9) com notas inferiores a 2,4 (Figura 4).

Figura 2 - Médias gerais de sustentabilidade dos agroecossistemas.

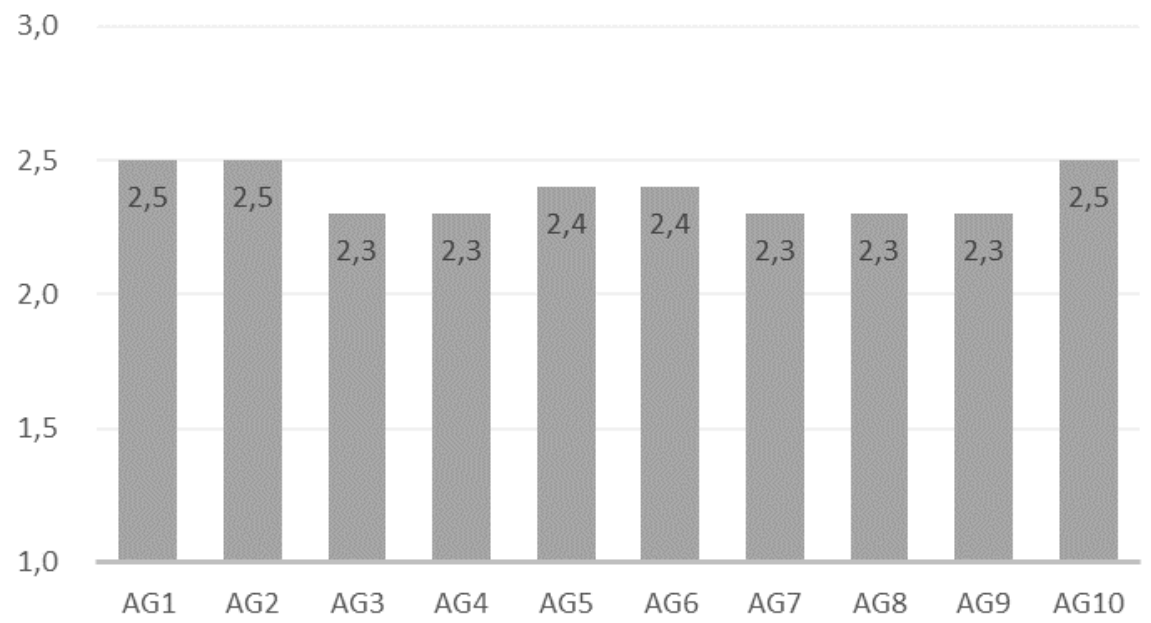

Fonte: Dados da pesquisa.

Dentre as propriedades avaliadas do grupo 1, três atingiram as maiores médias (2,5), sendo elas: AG1, AG2 e AG10. Nestes três agroecossistemas ID foi o que mais contribuiu para esse bom desempenho, apresentando a nota máxima (3,0). No AG1, IS, IANA e IRH foram os que apresentaram os valores mais baixos com 2,2, 2,3, e 2,4 respectivamente. A nota de IS foi prejudicada por fatores como a qualidade razoável, dificuldade para manejar, uso parcial de aração e a falta de práticas conservacionistas do solo em certas áreas. A assistência técnica insatisfatória, retorno parcial ao sistema convencional e o uso de poucas técnicas agroecológicas foram os fatores que contribuíram para que o indicador IANA apresentasse um dos menores valores. Já a pouca disponibilidade de água em períodos mais secos e a sua qualidade razoável foram os motivos para que o IRH também apresentasse uma nota baixa. No AG2, IS $(2,2)$ e IANA $(2,3)$ foram os indicadores com as menores médias, necessitando de maior atenção para aumentar a média geral de sustentabilidade. Certa dificuldade de manejar o solo, falta de cobertura vegetal em algumas áreas e o uso de aração foram os fatores que contribuíram para IS apresentasse a menor média. A média do IANA foi afetada pelo retorno parcial do manejo convencional, assistência técnica não satisfatória, baixa inovação do manejo agroecológico, rendimento igual ao convencional e a falta de uso de algumas técnicas e insumos agroecológicos. E 
no AG10, IS apresentou a menor média $(2,0)$, sendo afetada pela qualidade razoável, ocorrência de sulcos e valetas e a inexistência de práticas conservacionistas.

AG5 e AG6 apresentaram médias de sustentabilidade iguais, com 2,4 cada. Em ambos agroecossistemas ID foi o indicador de maior êxito, com a maior nota $(3,0)$. No AG5, IANA apresentou a menor média, com 1,8. A falta de atuações participativas em atividades sociais, uso de poucas técnicas e insumos agroecológicos, inexistência de assistência técnica e inovação do manejo agroecológico prejudicaram a média do IANA. No AG6, IANA e ISE apresentaram os menores valores, com 2,1 e 2,2 respectivamente. Fatores como a pouca busca por alternativas e inovação do manejo agroecológico, inexistência de assistência técnica, rendimento inferior ao sistema de produção convencional e pouco uso de insumos e técnicas agroecológicas prejudicaram a média de IANA. Já a média de ISE foi afetada pela insatisfação com o retorno financeiro e a dificuldade de quitar as dívidas.

Figura 3 - Gráfico com as médias dos indicadores dos agroecossistemas com notas igual ou superior a 2,4.
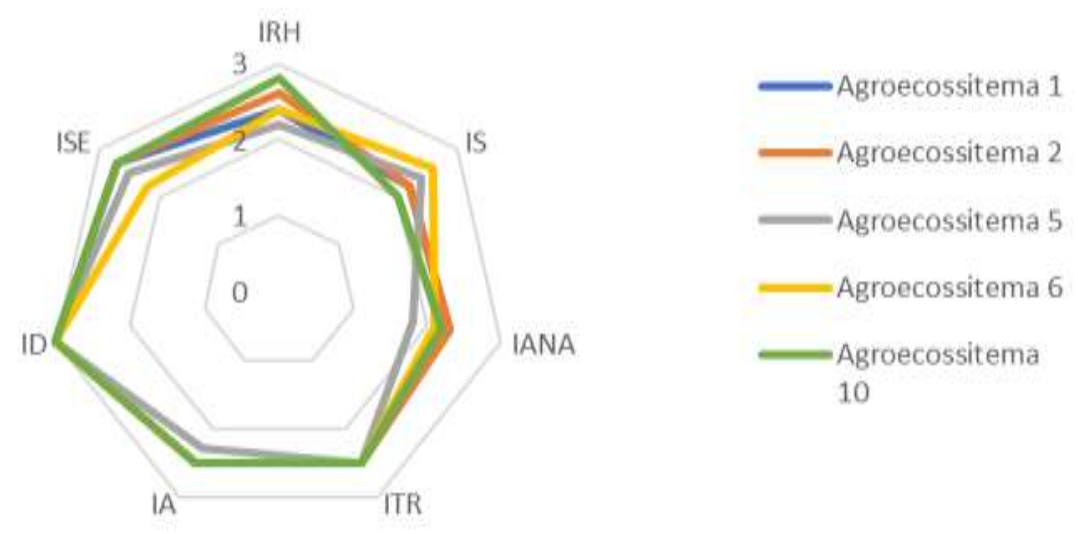

Fonte: Dados da pesquisa.

No grupo 2, AG3, AG4, AG7, AG8 e AG9 apresentaram médias de sustentabilidade idênticas, com 2,3 cada. Em AG3 e AG4, ID foi o indicador que apresentou a maior média $(3,0)$. No AG3, IS $(2,0)$ e IRH $(2,0)$ apresentaram as menores médias. A qualidade razoável, dificuldade de manejo, uso de aração e a falta de algumas práticas conservacionistas comprometeram o seu bom resultado. Já a pouca disponibilidade em períodos mais secos, poucas estratégias para conservação e o lançamento parcial do esgoto domiciliar afetaram a média do IRH. No AG4, IS, IRH obtiveram as menores médias, com 2,0 cada. A nota de IS foi afetada pela qualidade razoável, dificuldade para manejo, falta de cobertura vegetal e práticas conservacionistas. Já os fatores como a qualidade razoável, pouca disponibilidade em períodos secos, poucas estratégias de conservação e lançamento parcial de esgoto afetaram a nota de IRH.

No AG7, a maior nota foi do IS $(2,6)$ e o menor do IANA $(2,0)$. A pouca atuação participativa em atividades sociais, inexistência de alternativas e assistência técnica, rendimento inferior ao convencional e o uso parcial de técnicas e insumos afetaram a nota de IANA. Tanto em AG8 como AG9, ID indicou a maior média (3,0). No AG8, IANA e ITR obtiveram as menores médias, com 2,0 cada. Fatores como a pouca busca por alternativas, assistência técnica insatisfatória, pouca inovação do manejo, pouco entendimento sobre os aspectos ambientais, rendimento inferior em relação ao sistema convencional e o uso parcial de técnicas e insumos agroecológicos prejudicaram a média de IANA. Já a nota de ITR foi afetada pela baixa qualidade dos serviços essenciais à família (acesso a serviços de saúde, educação, transporte, estrutura da casa e lazer), dúvida em continuar com o manejo agroecológico, necessidade de contratar mão de obra, atividades pesadas e com pouco descanso e dúvida em relação à satisfação com a atividade. 
Em AG9, IANA e ITR apresentaram as menores médias, com 2,1 cada. IANA foi afetado por fatores como a falta atuações participativas em grupos sociais, retorno parcial ao sistema de produção convencional, assistência técnica insatisfatória, pouco entendimento dos aspectos ambientais e pouco uso de técnicas e insumos agroecológicos. Já ITR foi prejudicado pela baixa qualidade dos serviços essenciais à família (acesso a serviços de saúde, educação, transporte, estrutura da casa e lazer), quantidade de mão de obra familiar insuficiente, necessidade de contratar terceiros e atividade agrícola pesada e com pouco descanso.

Figura 4 - Gráfico com as médias dos indicadores dos agroecossistemas com notas inferiores a 2,4.
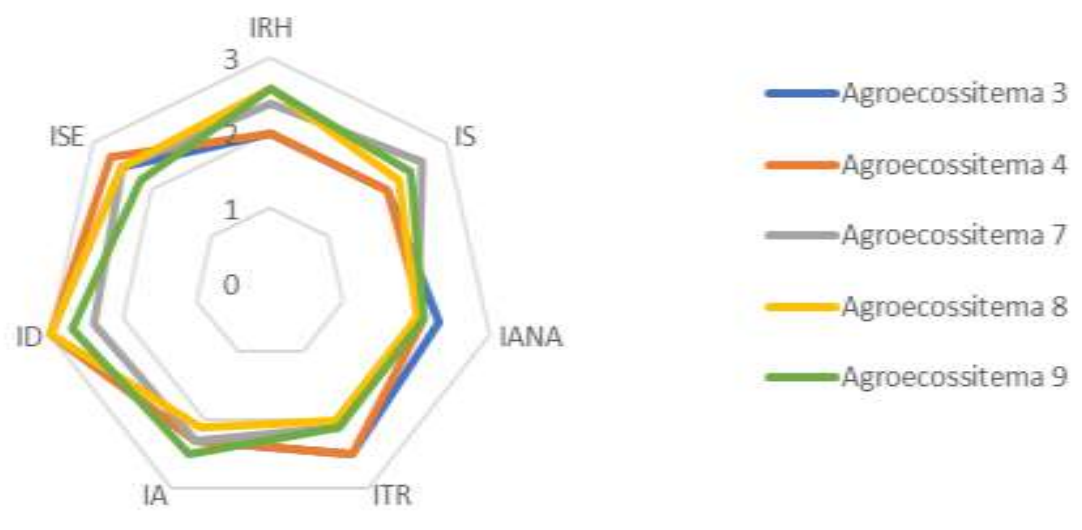

Fonte: Dados da pesquisa.

\subsection{Indicações gerais para os agroecossistemas}

Para que os agroecossistemas avaliados consigam aumentar sua média de sustentabilidade, faz-se necessário realizar algumas ações voltadas às práticas conservacionistas do solo como, adubação verde, cobertura morta e/ou vegetal e plantio direto, pois, estas tendem a melhorar a sua estrutura química e física. Em contraponto, deve-se reduzir o uso de práticas danosas como a aração e gradagem. Também, é primordial que ocorra um maior uso de técnicas agroecológicas como rotação de culturas, novos defensivos naturais, cercas vivas, plantas atrativas e repelentes. Para resolver os problemas voltados a falta de água nos períodos mais secos, os proprietários devem investir em estratégias de captação de água da chuva em cisternas e reservatórios naturais, e aumento de vegetação nas proximidades dos poços e dos barreiros, bloqueando o acesso de animais em seus entornos. O tratamento e reaproveitamento também são opções em ambientes com escassez de água. Rodrigues (2016) ressalta que o uso dessas práticas conservacionistas do solo e técnicas agroecológicas têm um importante papel na superação do desafio da expansão da produtividade, na manutenção da produção agrícola e na conservação de recursos hídricos e do solo.

As falhas da assistência técnica podem ser minimizadas pela intensificação da relação agricultor/universidade, uma vez que, já existe um elo entre os produtores e a UFRPE/UFAPE, que dispõe do papel de extensão rural. A busca pelos serviços de assistência técnica rural disponibilizada gratuitamente pelo Instituto Agronômico de Pernambuco (IPA) também é uma opção viável. Ainda, faz-se necessário que os produtores coloquem em prática a gestão dos dados financeiros, o que facilita a administração das dívidas e investimentos futuros, e que busquem o auxílio de programas de crédito voltados ao desenvolvimento e fortalecimento da agricultura familiar como o PRONAF e o AgroAmigo (Nunes, Santos \& Lara, 2020). E por fim, sugere-se o estimulo à participação das famílias em atividades sociais associações comunitárias e cooperativas. 


\section{Considerações Finais}

A execução das seis etapas do MESMIS possibilitou realizar uma avaliação de sustentabilidade dos agroecossistemas de forma a compreender os aspectos socioeconômicos e ambientais. A caracterização da área permitiu observar um panorama geral e a relação dos agricultores com o agroecossistema, estimulando a autocrítica. A indicação dos pontos críticos e de destaque teve como papel, ajudar a sanar os principais gargalos durante o processo de transição agroecológica. A determinação dos indicadores, considerando a opinião dos agricultores, os fatores positivos e negativos e o estudo da literatura possibilitaram estabelecer um conjunto de avaliação direcionada à compreensão da situação atual dos agroecossistemas avaliados. A mensuração dos indicadores permitiu valorar de forma prática as informações levantadas. Com a síntese e integração dos resultados identificou-se os pontos fortes e fracos. E por fim, as indicações gerais para os agroecossistemas direcionou caminhos para que os proprietários consigam cada vez mais atingir a sustentabilidade.

Portanto, o MESMIS apresentou-se como um instrumento de gestão ambiental capaz de tratar as peculiaridades e percepções dos atores, bem como, o consenso do que é prioridade para o fortalecimento como grupo agroecológico. Percebeuse ainda, que os agricultores entendem a sustentabilidade como um processo contínuo, com preocupações ecológicas, análise crítica ao fator econômico e uma reflexão social que favorece o desenvolvimento criativo e organizacional, valorizando seus produtos, fortalecendo a agricultura familiar e difundindo suas vantagens. Entretanto, estes resultados refletem um panorama atual e para futuros trabalhos, sugere-se a implementação de novos indicadores, tendo em vista a sua dinâmica de tendência e a necessidade de uma representação holística.

\section{Referências}

Acosta-Alba, I., \& Werf, H. M. G. D. (2011). The Use of Reference Values in Indicator: Based Methods for the Environmental Assessment of Agricultural Systems. Sustainability, 3(2), 424-442.

Alcázar, P., Espejel, I., Reyes-Orta, M., \& Arredondo-García, M. C. (2020). Retrospective assessment as a tool for the management of sustainability in diversified farms. Agroecology and Sustainable Food Systems, 44(1), 30-53.

Astier, M., \& Hollans, J. (2005). Sustentabilidad y campesinado: seis experiencias agroecológicas enLatinoamérica. México: Mundi-prensa.

Bélanger, V., Vanasse, A., Parent, D., Allard, G., \& Pellerin, D. (2012). Development of agri-environmental indicators to assess dairy farm sustainability in Quebec, Eastern Canada. Ecological indicators, 23, 421-430.

Caporal, F. R., \& Costabeber, J. A. (2002). Análise multidimensional da sustentabilidade. Agroecología e desenvolvimento rural sustentavél, 3 (3), 70-85.

Chaparro-Africano, A. M. (2019). Toward generating sustainability indicators for agroecological markets. Agroecology and Sustainable Food Systems, 43(1), $40-66$.

Ferraz, J. M. G. (2003). Indicadores de Sustentabilidade: Aspectos Teóricos. Ferraz, J. M. G., Marques, J. F., \& Skorupa, L. A. (In.), Indicadores de sustentabilidade em agroecossitemas. Jaguariúna: Embrapa Meio Ambiente.

Gliessman, S. R. (2014). Agroecology: the ecology of sustainable food systems. CRC press.

Hirakuri, M. H., CASTRO, C. D., Franchini, J. C., Debiasi, H., PROCOPIO, S. D. O., \& Balbinot Junior, A. A. (2014). Indicadores de sustentabilidade da cadeia produtiva da soja no Brasil. Embrapa Soja-Documentos (INFOTECA-E).

López-Ridaura, S., Van K. H., Ittersum, M. K.V, \& Leffelaar, P. A. (2005). Multiscale methodological framework to derive criteria and indicators for sustainability evaluation of peasant natural resource management systems. Environment, development and sustainability, 7(1), 51-69.

Losada, R., Gómez-Ramos, A., \& Rico, M. (2019). Rural areas receptivity to innovative and sustainable agrifood processes. A case study in a viticultural territory of Central Spain. Regional Science Policy \& Practice, 11(2), 307-327.

Masera, O., Astier, M., \& López-Ridaura, S. (2000). Sustentabilidad y manejo de recursos naturales: el marco de evaluación MESMIS. México: MundiPrensa.

Matos Filho, A. M. (2004). Agricultura orgânica sob a perspectiva da sustentabilidade: uma análise da região de Florianópolis/SC, Brasil. Dissertação (Mestrado em Engenharia ambiental). Universidade Federal de Santa Catarina, Florianópolis/SC, Brasil.

Nascimento, R. C. M., Guilherme, B. C., de Araújo, M. C. B., Magarotto, M., \& Silva-Cavalcanti, J. S. (2018). Uso de Indicadores Ambientais em áreas costeiras: uma revisão bibliográfica. Revista Brasileira de Meio Ambiente, 2(1), 52-69. 
Research, Society and Development, v. 10, n. 17, e23101724478, 2021

(CC BY 4.0) | ISSN 2525-3409 | DOI: http://dx.doi.org/10.33448/rsd-v10i17.24478

Nicholls, C. I., Altieri, M. A., Dezanet, A., Lana, M., Feistauer, D., \& Ouriques, M. (2004). A rapid, farmer-friendly agroecological method to estimate soil quality and crop health in vineyard systems. Biodynamics, 33-39.

Nunes, E. S., Santos, E. A., \& Lara, F. L. (2020). Agroamigo: Uma Análise De Sua Importância Para Os Pequenos Agricultores Do Nordeste Brasileiro. Revista de Ciências Contábeis, 79-80.

Paoli, L., Grassi, A., Vannini, A., Maslaňáková, I., Bil'ová, I., Bačkor, M., \& Loppi, S. (2015). Epiphytic lichens as indicators of environmental quality around a municipal solid waste landfill (C Italy). Waste Management, 42, 67-73.

Pilouk, S., \& Koottatep, T. (2017). Environmental performance indicators as the key for eco-industrial parks in Thailand. Journal of Cleaner Production, 156, 614-623.

Pinsonneault, A., \& Kraemer, K. L. (1993). Survey research in management information systems: an assessement. Journal of Management Information System, 10 .

Rodrigues, A. S. (2016). Avaliação do impacto do Projeto Hora de Plantar sobre a sustentabilidade dos agricultores familiares da Microrregião do Cariri (CE): o caso do milho híbrido (Tese de doutorado). Universidade Federal do Ceará, Fortaleza.

Sarandón, S. J., \& Flores, C. C. (2009). Evaluación de la sustentabilidad en agroecosistemas: una propuesta metodológica. Agroecología, 4, 19-28.

Souza, R. T. M., Martins, S. R., \& Verona, L. A. F. (2017). A metodologia MESMIS como instrumento de gestão ambiental em agroecossistemas no contexto da Rede CONSAGRO. Agricultura familiar: pesquisa, formação e desenvolvimento, 11(1), 39-56.

Verona, L. A. F. (2008). Avaliação de sustentabilidade em agroecossistemas de base familiar e em transição agroecológica na região sul do Rio Grande do Sul. Tese (Doutorado em Agronomia). Universidade Federal de Pelotas, Pelotas/RS, Brasil. 